Jelena Krstić ${ }^{\star}$, Nino Ćorić

${ }^{1}$ Economics Institute, Belgrade, Serbia

${ }^{2}$ University of Mostar, Faculty of Philosophy, Bosnia and Herzegovina

\title{
Public Health Communication: Skin Cancer Prevention Implications
}

DOI: 10.7595/management.fon.2021.0036

Abstract:

Research question: What are the characteristics of the target population which public health messages should be tailored to, in order to contribute to skin cancer prevention and early detection? Motivation: The implementation of preventive behaviour is of key importance taking into account the global increase in the incidence of skin cancer over the past decades. Communication campaigns represent an effective tool in creating awareness and education of population on harmful effects of exposure to UVR and a necessity of conducting preventive measures. The basis for creating such campaigns is to examine the knowledge, behaviour and information habits of target population. Idea: To examine the knowledge and attitudes regarding harmful effects of exposure to UVR, as well as preventive practices of adult urban population and determine the main sources of information on this topic. Data: The research took place in the period March-May 2018 in Belgrade and was based on surveing of 237 adult respondents from Belgrade. The sample was acquired by using the method of convenience sampling. Tools: The questionnaire consited of close-type questions with multiple choices of answers regarding sociodemographic characteristics, knowledge about risks of UVR exposure, preventive behaviour and preferred information sources. It was distributed in paper to patients while waiting for their appointments. Obtained data were manually coded and analysed by using SPSS. Results: A majority of both women $(45.6 \%)$ and men $(42.9 \%)$ report that they use sunscreens regularly, but a larger percentage of men ( $25 \%$ vs. $11.9 \%)$, as well as older respondents did not use sunscreens at all. Women reported to spend longer hours sunbathing (41.9\% vs. 33\%) and using indoor tanning than men (17.6\% vs. 5.2\%). Youngest respondents (age 20-30) also claim to practice excessive sunbathing (52.6\%) and use indoor tanning (23.2\%). Older respondents consider them being at higher risk of skin cancer (68.2\% of those older than 60$)$. There is a higher level of awareness of female in comparison with male respondents regarding the importance of skin cancer screening $(62.3 \%$ vs. $44.7 \%$ ), as well as of university educated respondents. Television has been noted to be the most significant source of information (57.8\%), followed by internet sources (43.5\%) and printed media (40.5\%). Contribution: Knowledge, attitudes and behaviour, as well as preferred sources of information differ by gender, age and education of respondents so targeted public health campaigns should be tailored to specific characteristics of target groups.

Keywords: public health communication, skin cancer prevention, knowledge, attitudes, preventive behaviour, information sources.

JEL Classification: I18, I12, M39

\section{Introduction}

A dramatic increase in the prevalence of skin cancer at the global level has been recognized over the past decades. According to the World Health Organization, non-melanoma skin cancers were among six most common cancers in 2020, with 1.20 million registered cases worldwide (World Health Organization, 2021). In spite of various initiatives and increased public awareness of the risks and prevention of skin cancer, the incidence of non-melanoma and melanoma skin cancer continues to increase all around the world (Seite, Del Marmol, Moyal, \& Friedman, 2017; Lopez, Carvajal, \& Geskin, 2018).

Ultraviolet radiation (UVR) is detected as a main risk factor, so unprotected and extensive exposure to ultraviolet radiation can lead to skin cancer development (Bowman, Lewis, Lee, \& Yao, 2015; Watson, Holman, \& Maguire-Eisen, 2016). More importantly, skin cancer is can be prevented by applying certain patterns of behaviour - reduction of unprotected exposure to ultraviolet radiation (Thoonen, Osch, Vries, 
Jongen, \& Schneider, 2020), sun protection and screening. The increase in the knowledge of general population and, especially, risk groups, regarding this topic is particularly important in order to stimulate early detection of skin cancer (Kamell, Mitchell, \& Leslie, 2013). Empirical evidence confirmed that greater exposure to communication and education programmes led to increased sun protection behaviour (Reynolds et al., 2008).

Prevention programmes represent an efficient means to combat this public health issue (Tizek et al., 2019). Primary prevention programmes have the goal to reduce skin cancer risk behaviour of the population, by raising awareness on the topic and educating people about preventive practices (Nguyen et al., 2020; Parsons et al., 2018). Conduction of mass media informational and educational campaigns appears to be an effective tool for rising population's knowledge level and preventive behaviour (Calloway, Fricke, Carpenter, \& Yaroch, 2021). Such a comprehensive and holistic model of communication supplements other public health promotion approaches by its possibility to influence knowledge and attitudes of the target group members regarding risks of UV radiation exposure and discouragement of indoor tanning (Mayer et al., 2011; Watson et al., 2013; Lee \& Kang, 2018).

In order to develop effective communication strategies, it is necessary to get a valuable insight into awareness, attitudes and behavioural patterns of the target population, which is a necessary foundation for the development of tailored communication programs. These were the topic of the research of authors in different countries, such as Trad and Estaville (2017) in USA, Garcia-Montero et al. (2020) in Spain, Nguyen et al. (2020) in Vietnam and Sideris and Thomas (2020) in Australia. In accordance with the previous research which pointed out to valuable differences among demographic groups of study population, the authors have recognized the need to conduct a comprehensive research on this important topic in Serbia. Therefore, research objective was to examine the knowledge and attitudes regarding harmful effects of exposure to UV radiation, as well as preventive practices of adult urban population and determine the main sources of information on this topic.

The paper is organized in four sections. After the introductory part, study materials and methods are explained in the second section. The third section refers to research findings and discussion of the obtained results. Concluding remarks, as well as limitations of the study and guidelines for future research are given in the final, fourth section.

\section{Methods}

\subsection{Study population}

The research was conducted from March to May 2018. The sample included 237 respondents who were patients of one private health care institution in Belgrade, Serbia, and all were residents of this city. The survey sample was acquired by the method of convenience sampling. The patients were given the questionnaire in printed form to fill in while waiting for their appointments which were not related to dermatological problems or skin cancer. Patients were approached by researchers in the waiting room and they were asked to participate in the survey whose objectives and purpose were clearly explained to them. Eligible participants were patients older than 20 and no other condition was required. The research was conducted in accordance with ESOMAR ethical and professional guidance related to social research and data analytics. The participants gave oral consent for the participation. The participation of respondents was on voluntary basis and completely anonymous, so, complete protection of participants' personal data was assured during whole research process. The survey did not demand provision of any sensitive personal patients' data related to their medical histories and current health conditions.

\subsection{Research instrument}

The survey instrument (questionnaire) was developed based on literature review on this topic. The questionnaire included the following groups of questions:

- Demographic characteristics (gender, age, education, skin type);

- Knowledge and attitudes (SPF meaning and issues related to skin cancer preventive behaviour and risks)

- Behavioural patterns (application of sunscreen, time spent sunbathing, sunburning in the childhood, indoor tanning, measures of preventive behaviour)

- Main media sources of information about skin cancer prevention;

- Perceived most responsible subjects for the education of general public regarding skin cancer prevention and risk factors. 
The questionnaire contained solely close-type questions in order to ensure an easier coding and analysis. Demographic questions were put at the beginning of the questionnaire. After that, there were questions related to respondents' knowledge (choice between options), attitudes (5-point Likert scale) and behaviour (choice between options). At the end, questions related to sources of information were given in close-type form (choice between options).

\subsection{Statistical analysis}

The obtained data were manually coded and analyzed by using statistical software SPSS (v. 17.0). Comparisons were made by demographic variables - gender, age, education and, where applicable, skin type. The analysis was performed by using methods of descriptive statistics.

\section{Research Results and Discussion}

\subsection{Knowledge and attitudes}

Within the sample, there were 77 male respondents (32.5\%) and 160 female respondents (67.5\%). The sample was structured by age into four categories. Minimum age was 20 , and maximum 78 , while the mean age of respondents was 40.49 years. As regards education, the majority had higher education $(62.0 \%)$, while $37.1 \%$ had secondary school education and $0.8 \%$ had primary school education (Table 1 ).

Table 1: Structure of the survey sample

\begin{tabular}{|l|c|}
\hline & n (\% of the total sample) \\
\hline Gender & $160(67.5 \%)$ \\
\hline Female & $77(32.5 \%)$ \\
\hline Male & $57(24.1 \%)$ \\
\hline Age & $61(25.7 \%)$ \\
\hline $20-30$ & $58(24.5 \%)$ \\
\hline $31-40$ & $39(16.5 \%)$ \\
\hline $41-50$ & $22(9.3 \%)$ \\
\hline $51-60$ & \\
\hline$\geq 61$ & $147(62.0 \%)$ \\
\hline Education & $88(37.1 \%)$ \\
\hline Secondary education & $2(0.8 \%)$ \\
\hline Primary education &
\end{tabular}

The results indicated that there seems to be a reasonable level of knowledge of respondents regarding skin cancer prevention and hazards of overexposure to the sun. Sunscreen was noted as the most used means for sun protection, such was the case in some of the other research such as those performed by Seite et al., (2017) and Nguyen et al., (2020). The majority of both women (45.6\%) and men (42.9\%) claimed to use sunscreen with SPF30 regularly when sunbathing. However, almost one quarter of men did not use SPF sunscreen at all, while in case of women that percentage was lower (11.9\%). This is in accordance with previous findings which indicate that female patients are more likely to practice preventive behaviour than male (e.g., Cathcart et al., 2011; Nguyen et al., 2020; Seite et al., 2017; Sideris \& Thomas, 2020). Although a high number of respondents within all age groups claimed to use sunscreens with SPF, age as demographic factor still appears to be relevant when it comes to the usage of sunscreen. A larger number of older respondents stated not to have the habit of using sunscreen at all (25\% respondents from 51 to 60 and $45.5 \%$ older than 60 ). This is in accordance with the findings of Sideris and Thomas (2020) who found out that males and respondents over 60 were least likely to conduct sun protection measures. When it comes to education, there were differences, although not statistically significant, regarding usage of sunscreens. In particular, a higher percentage of respondents with secondary education did not use protective creams $(22.7 \%)$ in comparison with university educated respondents (10.9\%). Seite et al., (2017) also noted that individuals with lower education level were found to be least likely to conduct preventive measures. Skin type was also found to be an important factor for sunscreen application, since the majority of respondents with very light and light tone of skin, said that they used protective creams with higher SPF regularly, while the situation was worse when it comes to respondents with darker skin, since more than $20 \%$ stated they did not use it at all. This is noted in literature as "a sunscreen paradox" which explains that individuals who perceive themselves not to be at risk or being at a lower risk of skin cancer occurrence (mainly less sensitive 
skin types) may, therefore, pay less attention to proper usage of sunscreen, so the risk of sunburn may be increased (Autier, Boniol \& Dore, 2007).

The knowledge of respondents regarding the meaning of SPF in sunscreens was at a low level. Only $17.1 \%$ of men and $20 \%$ of women gave the right answer. The probability of giving the right answer rose with age categories. So, one quarter of respondents aged 51 to 60 gave the right answer, as well as $22.7 \%$ of respondents from the oldest group, while the percentage was lower in other age groups. A smaller percent of respondents with secondary education (14.8\%) than those with university education (21.9\%) gave the correct answer (Table 2). Similarly, earlier research also indicated that most sunscreen users actually did not understand what SPF means and, therefore, most often associate high SPF with "agents that block their tanning ability", which leads to disobeying application instructions (Stengel \& Fernandez, 2005). As noted in the literature, sun burns are often a consequence of less amount of sunscreen that is actually being applied in relation to the amount recommended by manufacturers, often because instructions are not clear to them (Szepietowski, Nowicka, Reich \& Melon, 2004).

Table 2: Knowledge of the meaning of SPF in sunscreens

\begin{tabular}{|c|c|c|c|c|}
\hline $\begin{array}{l}\text { Characteristics } \\
\text { of respondents }\end{array}$ & $\begin{array}{l}\text { Strength of } \\
\text { blocking the } \\
\text { tanning ability }\end{array}$ & $\begin{array}{l}\text { Time allowed } \\
\text { for sunbathing } \\
\text { before burns }\end{array}$ & $\begin{array}{l}\text { Percentage of } \\
\text { protective } \\
\text { substance }\end{array}$ & Don't know \\
\hline & \multicolumn{4}{|c|}{ n (\% of the total sample) } \\
\hline \multicolumn{5}{|l|}{ Gender } \\
\hline Female & 76 (32.2) & $32(13.6)$ & $35(14.8)$ & $17(7.2)$ \\
\hline Male & $37(15.7)$ & $13(5.5)$ & $11(4.7)$ & $15(6.4)$ \\
\hline \multicolumn{5}{|l|}{ Age } \\
\hline $20-30$ & $32(13.6)$ & $9(3.8)$ & $9(3.8)$ & $6(2.5)$ \\
\hline $31-40$ & $34(14.4)$ & $10(4.2)$ & $11(4.7)$ & $6(2.5)$ \\
\hline $41-50$ & $27(11.4)$ & 11(4.7) & $16(6.8)$ & $4(1.7)$ \\
\hline $50-60$ & $11(4.7)$ & $10(4.2)$ & $8(3.4)$ & $10(4.2)$ \\
\hline$>60$ & $9(3.8)$ & $5(2.1)$ & $2(0.8)$ & $6(2.5)$ \\
\hline \multicolumn{5}{|l|}{ Education } \\
\hline Primary & $0(0)$ & $0(0)$ & $1(0.4)$ & $1(0.4)$ \\
\hline Secondary & $39(16.5)$ & $13(5.5)$ & $19(8.1)$ & $17(7.2)$ \\
\hline University & $74(31.4)$ & $32(13.6)$ & $26(11.0)$ & $14(5.9)$ \\
\hline
\end{tabular}

\subsection{Behavioural patterns}

A larger number of women than men (41.9\% vs. 33\%) claimed that they spend from three to five hours sunbathing on daily basis during vacations. This is in accordance with findings of other authors who also noted that women were more prone to deliberate sunbathing than men (Stanton et al., 2004), even twice as likely as men, in order that they get a suntan faster (Branstrom, Ullen, \& Brandberg, 2004). Observed by age categories, the highest percentage of youngest respondents $(52.6 \%)$ regularly spent three to five hours sunbathing, while the percentage was lower in case of other age groups, which indicates that youngest respondents were more likely to consider long hours of sunbathing as acceptable behaviour. Asked about the sunburning at the early age, a larger number of men than women reported to have got sunburned five or more times during early age. Also, the percentage of those who sunburned at an early age decreases across age categories, so younger respondents seemed to be less careful. A very high percentage of those with very light skin tone $(35.7 \%)$ got sunburned, the same as one fifth of respondents with light and moderately dark skin tone. The research conducted by Parsons et al., (2018) in USA has also shown that more than a half of respondents reported being four or more times seriously sunburned at the early age. The obtained results indicate the alarming situation taking into consideration that skin cancer occurs more commonly in people with light tone of skin who spend a lot of time sunbathing.

An important issue in skin cancer prevention relates to the usage of indoor tanning, due to risks connected with it. It is proved that exposure to UVR from indoor tanning devices (tanning booths, beds and sun lamps) increases the risk of skin cancer development, including melanoma as the deadliest type (Watson et al., 2013; Mayer, Swetter, Guild \& Geller, 2015; Parsons et al., 2018). The usage of indoor tanning was low among respondents, which represents a positive result of this research. As expected, a higher number of female respondents than male ones reported to use indoor tanning (17.6\% vs. $5.2 \%)$. Among those respondents who use indoor tanning, those aged 20 to 30 made the highest percentage (23.2\%). Younger respondents were 
more aware that usage of indoor tanning may cause the skin cancer, although they were also identified as its most frequent users. So, $82.1 \%$ of youngest respondents reported to be aware of the risks, as did $80.3 \%$ of those from 31 to $40,53.4 \%$ of those from 41 to $50,74.3 \%$ of those from 51 to 60 and $77.3 \%$ of those older than 60 (Table 3). Also, previous research pointed out that women are more likely to be indoor tanning users (Stanton et al, 2004; Trad \& Estaville, 2017) and some especially emphasized young females as the most common users of indoor tanning (Watson et al., 2013; Seidenberg, Mahalingam-Dhingra, Weinstock, Sinclair, \& Geller, 2015; Friedman, English \& Ferris, 2015). Also, the usage of indoor tanning is mostly practiced during the summer season (61.3\% of those who use tanning booths). While using tanning booths, one third of respondents got their skin burned, therefore, this indicates the excessive indoor tanning behaviour due to insufficient knowledge of possible consequences. Prevention campaigns appeared to be an effective means for education of population regarding harmfulness of indoor tanning. For example, as a result of prevention campaigning, the use of sunbed was reduced significantly in Denmark during 2007-2015 (Koster, Meyer, Andersson, Engholm \& Dalum, 2018). Also, as a result of a wider media coverage of health-related topics, national-level legislative changes may occur; such was the case with the California indoor tanning ban (Mayer et al., 2011). Even though the percentage of indoor tanning users was not high in this research, it is still important to invest communication efforts in changing the current social norms regarding the desirability of a tanned skin in order to reduce that harmful behaviour (Johnson et al., 2009).

Table 3: Using of indoor tanning

\begin{tabular}{|c|c|c|}
\hline \multirow{2}{*}{$\begin{array}{l}\text { Characteristics } \\
\text { of respondents }\end{array}$} & Yes & No \\
\hline & \multicolumn{2}{|c|}{ n (\% of the total sample) } \\
\hline \multicolumn{3}{|l|}{ Gender $^{*}$} \\
\hline Female & $28(11.9)$ & $131(55.5)$ \\
\hline Male & $4(1.7)$ & $73(30.9)$ \\
\hline \multicolumn{3}{|l|}{ Age $^{* *}$} \\
\hline $20-30$ & $13(5.5)$ & $43(18.2)$ \\
\hline $31-40$ & $8(3.4)$ & $53(22.5)$ \\
\hline $41-50$ & $6(2.5)$ & $52(89.7)$ \\
\hline $50-60$ & $4(1.7)$ & $35(14.8)$ \\
\hline$>60$ & $1(0.4)$ & $21(8.9)$ \\
\hline \multicolumn{3}{|l|}{ Education } \\
\hline Primary & $1(0.4)$ & $1(0.4)$ \\
\hline Secondary & $12(5.1)$ & $76(32.2)$ \\
\hline University & $19(8.1)$ & $127(53.8)$ \\
\hline \multicolumn{3}{|l|}{ Skin type } \\
\hline Very light & $2(0.8)$ & $12(5.1)$ \\
\hline Light & $13(5.5)$ & $90(38.1)$ \\
\hline Dark & $14(5.9)$ & $86(36.4)$ \\
\hline Very dark & $3(1.3)$ & $16(6.8)$ \\
\hline
\end{tabular}

The results showed gender differences related to the usage of sunscreens only during summer holidays. It seems that preventive behaviour knowledge levels are higher in case of women, as also noted by Owen, Fitzpatrick, Dolan and Gavin (2004). Men were less likely to practice preventive measures when they are exposed to the sun (wear protective hats, caps, sunglasses). A higher percentage of men considered that redness is a normal consequence of sun bathing (40\% vs $25 \%$ ). Also, it was found out that respondents who were familiar with the real meaning of SPF reported to use sunscreens in other settings than summer holidays and beaches (38.3\%). This points out to the lack of respondents' awareness of harmfulness of overexposure to sun during all seasons. It is necessary to apply preventive behaviour during the winter season when practicing winter sports, such as skiing and snowboarding since UV reflection from the snow surface brings an increased risk of skin cancer (Varedi et al., 2018). Results indicate that the largest number of youngest respondents never uses sunscreens with SPF during winter holidays, while the level of awareness rose with older groups. Education seems to be a significant factor when it comes to practicing preventive measures, spending time in sunshade and wearing protective clothing (hats, caps, sunglasses). So, a higher number of respondents with university education than those with secondary education conduct such preventive measures ( $85 \%$ vs. $47 \%$ ). A smaller number of respondents with higher education than those with secondary education considered that redness of a skin represents a normal consequence in the process of tanning ( $26 \%$ vs. $42 \%)$. 
Table 4: Evaluation of statements related to skin cancer preventive behaviour

\begin{tabular}{|c|c|c|c|c|c|}
\hline & Gen. & Age & Educ. & Skin & Know. \\
\hline I use sunscreen only during the holiday season & $\begin{array}{c}\mathrm{p}<0.0 \\
01\end{array}$ & - & - & - & $\begin{array}{c}\mathrm{p}<0.0 \\
1\end{array}$ \\
\hline $\begin{array}{l}\text { Facial creams that I use throughout the year contain } \\
\text { SPF }\end{array}$ & $\begin{array}{c}\mathrm{p}<0.0 \\
5\end{array}$ & - & - & - & - \\
\hline $\begin{array}{l}\text { Skin redness during sunbathing is a normal } \\
\text { occurrence in the process of tanning }\end{array}$ & $\begin{array}{c}\mathrm{p}<0.0 \\
1\end{array}$ & - & $\begin{array}{c}\mathrm{p}<0.0 \\
5\end{array}$ & - & - \\
\hline $\begin{array}{l}\text { I use sunscreen also during windy and cloudy } \\
\text { summer days }\end{array}$ & - & - & - & - & - \\
\hline $\begin{array}{l}\text { I also use the protective factor cream when I'm on } \\
\text { winter holidays }\end{array}$ & - & $\begin{array}{c}\mathrm{p}<0.0 \\
01\end{array}$ & $\begin{array}{c}\mathrm{p}<0.0 \\
5\end{array}$ & - & - \\
\hline $\begin{array}{l}\text { During exposure to the sun, I wear protective } \\
\text { clothing (hats, hats, sunglasses) }\end{array}$ & - & - & $\begin{array}{c}p<0.0 \\
5\end{array}$ & - & - \\
\hline $\begin{array}{l}\text { I spend most of my time on the beach sitting under } \\
\text { the umbrella }\end{array}$ & - & - & $\begin{array}{c}\mathrm{p}<0.0 \\
01\end{array}$ & - & - \\
\hline $\begin{array}{l}\text { I respect the experts' recommendations to avoid } \\
\text { exposure to the sun in the period from } 11 \text { am to } 3 \\
\text { pm during summer months }\end{array}$ & - & $\begin{array}{c}\mathrm{p}<0.0 \\
01\end{array}$ & $p<0.0$ & - & - \\
\hline $\begin{array}{l}\text { When I'm on vacation, I apply sunscreen in } \\
\text { accordance with the instructions on the packaging }\end{array}$ & - & - & $\begin{array}{c}\mathrm{p}<0.0 \\
01\end{array}$ & - & $\begin{array}{c}\mathrm{p}<0.0 \\
5\end{array}$ \\
\hline $\begin{array}{l}\text { I am aware that the appearance of skin cancer is } \\
\text { associated with excessive exposure to UV rays }\end{array}$ & - & - & $\begin{array}{c}p<0.0 \\
01\end{array}$ & - & - \\
\hline $\begin{array}{l}\text { I consider that I take the necessary measures to } \\
\text { protect myself from excessive exposure to the sun }\end{array}$ & - & - & - & - & - \\
\hline $\begin{array}{l}\text { Exposure to sun rays is beneficial for skin as it } \\
\text { stimulates the production of vitamin D }\end{array}$ & - & $\begin{array}{c}p<0.0 \\
5\end{array}$ & - & - & $\begin{array}{c}\mathrm{p}<0.0 \\
5\end{array}$ \\
\hline $\begin{array}{l}\text { Tanned skin is fashionable, so it is necessary to } \\
\text { sunbathe for this reason }\end{array}$ & - & - & $\begin{array}{c}p<0.0 \\
01\end{array}$ & $\begin{array}{c}p<0.0 \\
5\end{array}$ & - \\
\hline $\begin{array}{l}\text { I am aware that the emergence of melanoma and } \\
\text { other forms of carcinoma of the skin is associated } \\
\text { with excessive exposure to UV radiation in indoor } \\
\text { tanning booths }\end{array}$ & - & $\begin{array}{c}p<0.0 \\
5\end{array}$ & $p<0.0$ & - & $\begin{array}{c}\mathrm{p}<0.0 \\
5\end{array}$ \\
\hline $\begin{array}{l}\text { I do not think I belong to a critical group when } \\
\text { melanoma and other skin tumors are concerned }\end{array}$ & - & $\begin{array}{c}\mathrm{p}<0.0 \\
5\end{array}$ & - & - & - \\
\hline
\end{tabular}

When it comes to respecting the recommendations regarding preventive measures provided by different sources (health practitioners, experts, media etc.), differences were noted in case of age and education categories. The perception of the importance of such recommendations rose in accordance with respondents' age. Such recommendations were important to approximately $50 \%$ of the respondents in the age group from 20 to $30 ; 75.2 \%$ of those from 31 to $40 ; 77.6 \%$ of those from 41 to $50 ; 84.6 \%$ of those from 51 to 60 and $81.8 \%$ of those older than 60 . For respondents with higher education it was less likely to forget to reapply sunscreen when necessary $(34.7 \%$ vs. $51.1 \%)$. Considering that sunburns often occur as a result of forgotten reapplication of sunscreen, some of marketing communication strategies should be designed and implemented simply as a 'reminder' communication (Johnson et al., 2009).

As was shown in some other research (e.g., Cathcart et al., 2011), respondents were familiar that inappropriate and excessive exposure to sun could cause skin cancer. However, in practice, individuals may face conflicting messages about risks and benefits of moderate sun exposure, which may lead to wrong perception of desirable behaviour (Klein et al., 2014). Knowledge levels of respondents of different age categories regarding the fact that overexposure to UVR may be connected with the development of skin cancer differed slightly. Besides being more aware of risks, older respondents were more familiar with certain positive consequence (vitamin $D$ synthesis) as a consequence of moderate sunbathing. A majority of respondents (67.9\%) from the age category 20 to 30, agreed with that, while one quarter wasn't familiar with that. Respondents old 31 to 40 mainly agreed (67.2\%). Slightly more than half of respondents from the group from 41 to 50 agreed, and slightly more than one fifth did not know that moderate exposure to sun may have such benefit. A higher percentage of respondents from 51 to $60(77 \%)$ reported to be aware of that, as well as $81.8 \%$ of respondents older than 60 .

The results differed between age categories in attitudes of those belonging to the critical group when it comes to the development of skin cancer. Respondents from the youngest group in $37.5 \%$ of cases considered themselves being at some risk, as well as $42.6 \%$ of respondents from age group 31 to 40 . More 
than $50 \%$ of respondents from age groups 41 to 50 and 51 to 60 reported to consider themselves being at risk. Older respondents were more likely to consider them being at higher risk, so $68.2 \%$ of those older than 60 expressed their concern of being under higher risk. There are identified benefits of screening when it comes to prevention of skin cancer (Brunssen, Waldmann, Eisemann \& Katalinic, 2017). More men than women stated that they did not feel it is necessary to go for skin examination and dermoscopy $(55.3 \%$ vs. $32.7 \%$ ), which indicates a higher level of awareness of female respondents in this regard. This is in accordance with previous findings that women demonstrate a more considerable concern about skin cancer and consequences of UVR exposure than men. On the other hand, women also report higher rates of deliberate sunbathing and indoor tanning use. The research of Nguyen et al., (2020) has shown that almost $40 \%$ of respondents considered that they were at risk of skin cancer, but women were less aware of their skin cancer risk. A significant percentage of respondents of all age groups had never conducted screening and never considered it to be necessary (from 30-40\%), although that percentage was the lowest in case of the oldest group. On the other hand, the percentage of those who understood the necessity was high, but, despite that, they had never practiced it. A higher percentage of university educated respondents went to screening, more than those with secondary education $(29.5 \%$ vs. $12.6 \%)$. In general, the percentage of respondents who performed skin examination and dermoscopy was very low, which indicates the lack of awareness on the necessity of timely screening. It was also significantly lower than was the case in research performed in Italy by Suppa et al., (2014). Observing by skin types, it is notable that respondents with lighter skin were more concerned with this topic $(35.7 \%$ of those with very light skin tone performed the screening, as well as $23.3 \%$ of respondents with light skin tone, $22.2 \%$ with moderately dark skin tone and $15.8 \%$ with darker skin tone). So, the percentage was the lowest in case of those with dark skin tone, probably as they consider themselves to be under low risk of skin cancer development or not to be at risk at all (Table 5).

Table 5: Performance of skin examination and dermoscopy

\begin{tabular}{|c|c|c|c|c|}
\hline \multirow{2}{*}{$\begin{array}{l}\text { Characteristics } \\
\text { of respondents }\end{array}$} & No need & Not yet & $\begin{array}{l}\text { Yes, but not } \\
\text { regularly }\end{array}$ & Every year \\
\hline & \multicolumn{4}{|c|}{ n (\% of the total sample) } \\
\hline \multicolumn{5}{|l|}{ Gender* } \\
\hline Female & $52(22.1)$ & $63(26.8)$ & $39(16.6)$ & $5(2.1)$ \\
\hline Male & $42(17.9)$ & $18(7.7)$ & $15(6.4)$ & $1(0.4)$ \\
\hline \multicolumn{5}{|l|}{ Age } \\
\hline $20-30$ & $26(11.1)$ & $16(6.8)$ & $12(5.1)$ & $2(0.9)$ \\
\hline $31-40$ & $20(8.5)$ & $22(9.4)$ & $16(6.8)$ & $2(0.9)$ \\
\hline $41-50$ & $22(9.4)$ & $20(8.5)$ & $14(6.0)$ & $2(0.9)$ \\
\hline $50-60$ & $18(7.7)$ & $15(6.4)$ & $6(2.6)$ & $0(0)$ \\
\hline$>60$ & $8(3.4)$ & $8(3.4)$ & $6(2.6)$ & $0(0)$ \\
\hline \multicolumn{5}{|l|}{ Education $^{\star \star}$} \\
\hline Primary & $2(0.9)$ & $0(0)$ & $0(0)$ & $0(0)$ \\
\hline Secondary & $47(20.0)$ & $26(11.1)$ & $11(4.7)$ & $3(1.3)$ \\
\hline University & $45(19.1)$ & $55(23.4)$ & $43(18.3)$ & $3(1.3)$ \\
\hline \multicolumn{5}{|l|}{ Skin type } \\
\hline Very light & $5(2.1)$ & $4(1.7)$ & $5(2.1)$ & $0(0)$ \\
\hline Light & $35(14.9)$ & $40(17.0)$ & $24(10.2)$ & $4(1.7)$ \\
\hline Dark & 43 (18.3) & $33(14.0)$ & $22(9.4)$ & $1(0.4)$ \\
\hline Very dark & $11(4.7)$ & $4(1.7)$ & $3(1.3)$ & $1(0.4)$ \\
\hline
\end{tabular}

\subsection{Sources of information}

For male and female respondents of all age categories and education levels, the most suitable sources of skin cancer communication and information were healthcare providers and media. The importance of health care providers in relation to the implementation of health communication efforts that can reach target groups, contribute to their health-related education and promote the adoption of health-related preventive behaviour is identified in literature (e.g., Cokkinides, Kirkland, Andrews, Sullivan, \& Lichtenfeld, 2009; Friedman et al., 2015). Informational and educational campaigns are based on mass media as a powerful tool in healthrelated education of target groups of population (Dobbinson et al., 2008). Television was noted to be the most significant media since $57.8 \%$ of respondents watched some content dedicated to skin cancer prevention. Some respondents $(15.2 \%$ of them) watched such programme only during public campaigns, and considered that this topic was not promoted continually. Eleven percent of respondents saw a television programme dedicated to prevention, but were not interested in that topic and $14.3 \%$ thought that, in general, there was a lack of such content on television. Observed by gender, a larger number of male respondents 
than female respondents were not interested in watching a TV programme on this topic (18.4\% vs. $7.6 \%)$. Radio appeared not to be a significant media form for dissemination of this type of information since $47.3 \%$ of respondents had never heard such content on the radio.

The results indicate that printed media represents the most important source of information on the topic of prevention for $40.5 \%$ of respondents. Thirteen percent of respondents read on this topic only during specialized campaigns, while $6.3 \%$ were not interested in reading such content even though they had the opportunity to do so. A smaller percent (8.4\%) did not remember having ever seen such content in printed media. Gender, age and education were found to be important factors in this aspect. More male than female respondents ( $44.7 \%$ vs. $39.5 \%)$ selected daily newspapers as their preferred choice. Magazines dedicated to health and beauty were more often selected by women than men ( $37.6 \%$ vs $15.8 \%)$. This genre of magazines often focusses on providing health-promoting messages, through texts and advertisements, with the goal to educate women and raise their awareness on certain topics. Women demonstrated a higher knowledge on this topic than men in the light of reading women's magazines that cover skin cancer and tanning-related contents (Cho, Hall, Kosmoski, Fox \& Mastin, 2010). It is notable that women's magazines publish more articles on skin cancer prevention than men's magazines (McWhirter \& Hoffman-Goetz, 2015). Therefore, printed media, and especially magazines, represent an appropriate channel for dissemination of skin cancer information. Due to their potential to influence women's attitudes and behaviours, health and beauty magazines represent an important medium for health-related communication with women as a target group (Basch, Ethan, Clarke Hillyer \& Berdnik, 2014). However, despite the potential for conveying messages, there is a significant pool of research evidence that magazines, and printed media in general, often fail to address the issue of skin cancer prevention in a sufficient and appropriate manner (Kemp et al., 2011; Dixon, Warne, Scully, Wakefield \& Dobbinson, 2011; Cokkinides et al., 2009; McWhirter \& Hoffman-Goetz, 2016; McWhirter \& Hoffman-Goetz, 2015). Magazines were the dominating choice for younger respondents (35.7\% of those from 20 to 30$)$, while daily newspapers were a preferred choice of three older age groups $(47.4 \%$ of respondents from 41 to 50 , half of the other two). Daily newspapers were selected as a popular source of information by respondents with secondary school (51.7\%), while university educated respondents selected specialized magazines as their preferred source of information. So, it is obvious that television and newspapers can support educational campaigns by ensuring the distribution of key messages regarding preventive behaviour to target groups (Kemp, Eagle \& Verne, 2011; Basch, Clarke Hillyer \& Basch, 2013).

Table 6: The most important sources of communication and information on skin cancer prevention

\begin{tabular}{|l|c|c|c|c|}
\hline \multicolumn{1}{|c|}{ Media } & Gender & Age & Education & Knowledge \\
\hline Television & $\mathrm{p}<0.001$ & - & - & - \\
\hline Radio & - & - & - & - \\
\hline Printed media & $\mathrm{p}<0.001$ & $\mathrm{p}<0.05$ & $\mathrm{p}<0.001$ & - \\
\hline Internet & - & - & - & - \\
\hline Brochures & $\mathrm{p}<0.001$ & - & - & - \\
\hline
\end{tabular}

However, while television is still considered to be the most powerful motivator, the significance of the Internet and social media cannot be ignored, especially in case of younger people (Johnson et al., 2009). The Internet is widely used as media for searching for information regarding skin cancer (Tizek et al., 2019; Hopkins \& Secrest, 2019). The results indicate that the Internet is indeed an important media vehicle for skin cancer prevention education, especially web sites dedicated to health-related topics which appeared to be a significant media source for a majority of respondents (43.5\%). Ten percent of respondents have read such information on websites of health institutions, $8.0 \%$ on forums/blogs dedicated to health care and $9.3 \%$ in online editions of magazines. Also, more than one quarter of respondents have never searched for such information on the Internet due to the lack of their personal motivation to do so. Klein et al., (2014) warned that an increasing popularity of the Internet as a channel for dissemination of skin cancer related content carry certain potential problems as "cancer myths" can spread faster virally. Such "myths" can bring confusion to Internet users, especially in cases when there is a lack of credible sites hosted by government or academic institutions, or in case information presented on those sites is not understandable to all target groups.

One of the common segments of educational campaigns is the distribution of brochures and other similar informative material. Approximately $60 \%$ of respondents received brochures on the topic of skin cancer prevention at some point, out of which $44.7 \%$ read them carefully and $16.5 \%$ were not interested in doing that. A significant percentage $(37.1 \%)$ of respondents noted that they have never received any informative material on this topic. There is a difference between female and male respondents when it comes to willingness to read information provided in informative brochures. Women expressed more interest in reading such material than men (50.3\% vs. $35.5 \%)$. Also, a higher percentage of men who received such informative material wasn't interested in reading them, in comparison to women ( $27.6 \%$ vs. $11.5 \%)$. 
Table 7: Main sources of information on the topic of skin cancer prevention

\begin{tabular}{|c|c|c|c|c|c|}
\hline \multirow{2}{*}{$\begin{array}{l}\text { Characteristics } \\
\text { of respondents }\end{array}$} & $\begin{array}{c}\text { Ministry of } \\
\text { health }\end{array}$ & $\begin{array}{c}\text { Medical } \\
\text { practitioners }\end{array}$ & Media & Self-initiative & $\begin{array}{l}\text { Without } \\
\text { attitude }\end{array}$ \\
\hline & \multicolumn{5}{|c|}{$\mathbf{n}(\%$ of the total sample) } \\
\hline \multicolumn{6}{|l|}{ Gender } \\
\hline Female & $58(24.9)$ & $56(24.0)$ & $19(8.2)$ & $15(6.4)$ & $9(3.9)$ \\
\hline Male & $36(15.5)$ & $17(7.3)$ & $8(3.4)$ & $9(3.9)$ & $6(2.6)$ \\
\hline \multicolumn{6}{|l|}{ Age } \\
\hline $20-30$ & $24(10.3)$ & $14(6.0)$ & $7(3.0)$ & $7(3.0)$ & $4(1.7)$ \\
\hline $31-40$ & $24(10.3)$ & $20(8.6)$ & $7(3.0)$ & $6(2.6)$ & $3(1.3)$ \\
\hline $41-50$ & $21(9.0)$ & $27(11.6)$ & $6(2.6)$ & $1(0.4)$ & $2(0.9)$ \\
\hline $50-60$ & $18(7.7)$ & $5(2.1)$ & $5(2.1)$ & $6(2.6)$ & $4(1.7)$ \\
\hline$>60$ & $7(3.0)$ & $7(3.0)$ & $2(0.9)$ & $4(1.7)$ & $2(0.9)$ \\
\hline \multicolumn{6}{|l|}{ Education } \\
\hline Primary & $0(0)$ & $1(0.4)$ & $0(0)$ & $1(0.4)$ & $0(0)$ \\
\hline Secondary & $30(12.9)$ & $27(11.6)$ & $9(3.9)$ & $14(6.0)$ & $7(3.0)$ \\
\hline University & $64(27.5)$ & 45 (19.3) & $18(7.7)$ & $9(3.9)$ & $8(3.4)$ \\
\hline
\end{tabular}

All demographic categories of respondents perceived The Ministry of Health as the most responsible subject for education of general public on health-related topics. Health institutions were ranked in the second place by importance and responsibility to disseminate information on the topic of skin cancer prevention. Primary care physicians are seen to have an important role in skin cancer prevention by conducting counselling of patients on this topic (Perez \& Bashline, 2019). Comparing by gender, medical practitioners were selected by more male than female respondents ( $47.4 \%$ vs. $36.9 \%)$. More female than male respondents considered media to be the most important source of information on this topic. Self-responsibility for gathering such information was noted by a higher number of male respondents than female ones $(11.8 \%$ vs. $9.6 \%)$. Selfinitiative was also rated low in importance by female respondents in research on prevention of other cancer types (Cvijovic, Kostic-Stankovic, Krstic \& Stojanovic, 2016). Self-initiative was more valued by older respondents, respondents from 51 to 60 and respondents older than 60 . Respondents with higher education valued the role of the Ministry of health and media more than those with secondary education, while giving the lower importance to self-initiative in information gathering and knowledge acquiring (6.5\% vs. $16.1 \%)$.

\section{Conclusion}

Findings from this research indicate that knowledge, attitudes and behaviour, as well as preferred sources of information differ by gender, age and, up to a certain point, education of respondents. Women demonstrated a higher level of prevention knowledge and preventive behaviour than men, and older participants in the research also showed a more protective behaviour than younger ones. The conclusion is that targeted public health campaigns should be tailored to specific characteristics and needs of the target groups and be based on the using of specific channels of communication. These findings support the results obtained by other authors - that, in order to be effective and to bring social change, informational and educational programmes dedicated to cancer prevention must be focused and tailored in accordance with target group's attitudes, current knowledge level and informational and communication habits (Glanz et al., 2015; Calloway et al., 2021). By implementing preventive communication initiatives, bigger social changes can be expected. They could lead to higher public awareness on the harmful effects of exposure to UVR, and, consequently, to the reduction of skin cancer incidences and mortality rates. Segmentation and target group selection should be performed on the basis of demographic, psychographic and behavioural characteristics, so designed messages and selected communication channels can be more relevant to members of a certain intended target group (Dearing \& Kreuter, 2010). Those segmentation criteria are essential and should be taken into consideration by marketing communication programme developers; such was previously concluded by some other authors (e.g., Johnson et al., 2009).

The contribution of this research lies in the setting of empirical and theoretical bases for further investigation on this topic. However, this research has certain limitations which are related to survey organization and methods. First of all, a convenience sample was used, so participants were selected based on availability and willingness to participate. Although some useful results were obtained, the results are prone to significant bias, so results may not reflect the situation related to general population. Also, some factors that may be significant were not taken into consideration, like medical history of patients or cases of skin cancer incidence in their social circles, which could influence their knowledge and behaviour. Besides, the analysis was limited to descriptive statistics solely, so the upgraded research on this topic would benefit from the application of advanced statistical methods. Hence, the future research on this topic should cover larger samples selected based on some of probability sampling methods and should include more influential factors in the analysis. Also, the focus of the future research should be put on the potential for integration of different communication channels, especially digital ones, so individuals of different demographic profiles could obtain reliable information more efficiently. 


\section{REFERENCES}

[1] Autier, P., Boniol, M., \& Doré, J F. (2007). Sunscreen use and increased duration of intentional sun exposure: Still a burning issue. International Journal of Cancer, 121(1), 1-5 DOI: 10.1002/ijc.22745

[2] Basch, C., Clarke Hillyer, G., \& Basch, C. (2013). Descriptive analysis of articles and advertisements pertaining to skin cancer prevention in 2 popular US parenting magazines, 2000-2010. Preventing Chronic Disease,10, E48. DOI: 10.5888/pcd10.120200

[3] Basch, C.H., Ethan, D., Clarke Hillyer G., \& Berdnik, A. (2014). Skin cancer prevention coverage in popular us women's health and fitness magazines: An analysis of advertisements and articles. Global Journal of Health Science, 6(4), 42-48. DOI: 10.5539/gjhs.v6n4p42

[4] Bowman, D.M., Lewis, R.C., Lee, M.S., \& Yao, C.J. (2015). The growing public health challenges of exposure to ultraviolet radiation from use of indoor tanning devices in the United States. New Solutions, 25(2), 64-71. DOI: 10.1177/1048291115586416

[5] Branstrom, R., Ullen, H., \& Brandberg, Y. (2004). Attitudes, subjective norms and perception of behavioural control as predictors of sun-related behaviour in Swedish adults. Preventive Medicine, 39(5), 992-999. DOI:10.1016/j.ypmed.2004.04.004

[6] Brunssen, A., Waldmann, A., Eisemann, N., \& Katalinic, A. (2017). Impact of skin cancer screening and secondary prevention campaigns on skin cancer incidence and mortality: A systematic review. Journal of the American Academy of Dermatology, 76(1), 129-139. DOI: 10.1016/j.jaad.2016.07.045

[7] Calloway, E.E., Fricke, H.E., Carpenter, L.R., \& Yaroch, A.L. (2021). A qualitative exploration of indicators of health equity embeddedness among public health policy advocacy campaigns. Health Promotion Practice, DOI: 10.1177/1524839920981950

[8] Cathcart, S., DeCoster, J., Northington, M., Cantrell, W., Elmets, C., \& Elewski, B. (2011). Interest in cosmetic improvement as a marker for tanning behaviour: A survey of 1602 respondents. Journal of Cosmetic Dermatology, 10(1), 3-10. DOI:10.1111/j.1473-2165.2010.00522.x

[9] Cho, H., Hall, J., Kosmoski, C., Fox, R., \& Mastin, T. (2010). Tanning, Skin cancer risk, and prevention: A content analysis of eight popular magazines that target female readers, 1997-2006. Health Communication, 25(1), 1-10. DOI: 10.1080/10410230903265938

[10] Cokkinides, V., Kirkland, D., Andrews, K., Sullivan, K., \& Lichtenfeld, J.L. (2009). A profile of skin cancer prevention media coverage in 2009. Journal of the American Academy of Dermatology, 67(4), 570-575. DOI: $10.1016 /$ j.jaad.2011.11.920

[11] Cvijovic, J., Kostic-Stankovic, M., Krstic, G., \& Stojanovic, Lj. (2016). Marketing communication in the area of breast and cervical cancer prevention. Vojnosanitetetski pregled, 6(73), 544-552, DOI: 10.2298/VSP141020132C

[12] Dearing, M.W., \& Kreuter, J.W. (2010). Designing for diffusion: How can we increase uptake of cancer communication innovations? Patient Education and Counseling, 81, S100-S110. DOI: 10.1016/j.pec.2010.10.013

[13] Dixon, G., Warne, D., Scully, L., Wakefield, A., \& Dobbinson, J. (2011). Does the portrayal of tanning in Australian women's magazines relate to real women's tanning beliefs and behaviour? Health Education \& Behaviour, 38(2), 132-142. DOI: 10.1177/1090198110369057

[14] Dobbinson, S., Wakefileld, M., Jamesen, K., Herd, N., Spittal, M., Lipscombe, J., \& Hill, D. (2008). Weekend sun protection and sunburn in Australia: trends (1987-2002) and association with SunSmart television advertising. American Journal of Preventive Medicine, 34(2), 94-101. DOI: 10.1016/j.amepre.2007.09.024

[15] Friedman, B., English, J.C. 3rd, \& . (2015). Indoor Tanning, Skin Cancer and the Young Female Patient: A Review of the Literature. 28(4), 275-283. DOI: 10.1016/j.jpag.2014.07.015

[16] Garcia-Montero, P., Blázquez-Sánchez, N., Rivas-Ruíz, F., Millán-Cayetano, J.F., Fernández-Canedo, I., \& de Troya-Martín, M. (2020). Preventing skin cancer among staff and guests at seaside hotels. Journal of Cancer Education, 35(3), 501-508. DOI: 10.1007/s13187-019-01488-4

[17] Glanz, K., Volpicelli, K., Jepson, C., Ming, M., Schuchter, L., \& Armstrong, K. (2015). Effects of tailored risk communications for skin cancer prevention and detection: The PennSCAPE randomized trial. Cancer Epidemiology, Biomarkers \& Prevention, 24(2): 415-421. DOI: 10.1158/1055-9965.EPI-14-0926

[18] Hopkins, Z.H., \& Secrest, A.M. (2019). Public health implications of Google searches for sunscreen, sunburn, skin cancer, and melanoma in the United States. American Journal of Health Promotion, 33(4), 611-615. DOI: 10.1177/0890117118811754

[19] Johnson, K.M., Jones, S.C., \& Iverson, D. (2009). Guidelines for the development of social marketing programs for sun protection among adolescents and young adults. Public Health, 123, 6-10. DOI: 10.1016/j.puhe.2009.06.018

[20] Kamell Mitchell, J., \& Leslie, K.S. (2013). Melanoma death prevention: Moving away from the sun. Journal of American Academy of Dermatology, 68(6), 169-175. DOI: 10.1016/j.jaad.2012.09.028

[21] Kemp, G., Eagle, L., \& Verne, J. (2011). Mass media barrier social marketing interventions: The example of sun protection in the UK. Health Promotion International, 26(1), 37-45. DOI: 10.1093/heapro/daq048 
[22] Klein, W.M.P., Bloch, M., Hesse, B.W., McDonald, P.G., Nebeling, L., O’Connell, M.E., Riley, W.T., Taplin, S.H., \& Tesauro, G. (2014). Behavioural research in cancer prevention and control: A look to the future. American Journal of Preventive Medicine, 46(3), 303-311. DOI:10.1016/j.amepre.2013.10.004

[23] Koster, B., Meyer, M.K., Andersson, T.M., Engholm, G., \& Dalum, P. (2018). Sunbed use 2007-2015 and skin cancer projections of campaign results 2007-2040 in the Danish population: Repeated crosssectional surveys. BMJ Open, 8(8), e022094. DOI: 10.1136/bmjopen-2018-022094.

[24] Lee, M.J., \& Kang, H. (2018). Designing skin cancer prevention messages: Should we emphasize gains or losses? Message framing, risk type, and prior experience. American Journal of Health Promotion, 32(4), 939-948. DOI: 10.1177/0890117117729584

[25] Lopez, A.T., Carvajal, R.D., \& Geskin. L. (2018). Secondary prevention strategies for nonmelanoma skin cancer. Oncology, 32(4), 195-200.

[26] Mayer, J.A., Woodruff, S.I., Slymen, D.J., Sallis, J.F., Forster, J.L., Clapp, E.J., Hoerster, K.D., Pichon, L.C., Weeks, J.R., Belch, G.E., Weinstock, M.A., \& Gilmer, T. (2011). Adolescents' use of indoor tanning: A large-scale evaluation of psychosocial, environmental, and policy-level correlates. American Journal of Public Health, 101(5), 930-938. DOI: 10.2105/AJPH.2010.300079

[27] ., ., ., \& . (2015). The impact of indoor tanning legislation: newspaper coverage of the risks of indoor tanning before and after the California indoor tanning ban for minors. 30(1), 124-129. DOI: $10.1007 / \mathrm{s} 13187-014-0672-4$

[28] McWhirter, J.E., \& Hoffman-Goetz, L. (2016). Coverage of skin cancer risk factors and UV behaviours in popular U.S. magazines from 2000 to 2012. Journal of Cancer Education, 31(2), 382-388. DOI: $10.1007 / \mathrm{s} 13187-015-0808-1$

[29] ., \& . (2015). Skin deep: Coverage of skin cancer and recreational tanning in Canadian women's magazines (2000-2012). Canadian Journal of Public Health,106(4), 36-43. DOI: 10.17269/cjph.106.4795

[30] Nguyen, T.H.T., Tran, B.X., Nguyen, S.H., Latkin, C.A., Nguyen, C.T., Nguyen, S.H., Pham, H.Q., Ho, C.S.H., Ho, Roger, C.M., \& Oh, J-K. (2020). Attitudes about and practices for skin cancer prevention among patients with dermatological issues in Hanoi, Vietnam: A cross-sectional study. Environmental Health and Preventive Medicine, 25(1), 35. DOI: 10.1186/s12199-020-00875-4

[31] Owen, T., Fitzpatrick, D., Dolan, O., \& Gavin, A. (2004). Knowledge, attitudes and behaviours in the sun: The barriers to behavioural change in Northern Ireland. The Ulster Medical Journal, 73 (2), 96-104.

[32] Parsons, B.G., Gren, L.H., Simonsen, S.E., Harding, G., Grossman, D., \& Wu, Y.P. (2018). Opportunities for skin cancer prevention education among individuals attending a community skin cancer screening in a high-risk catchment area. Journal of Community Health, 43(2), 212-219. DOI: 10.1007/s10900-017-0406-8

[33] Perez, L.L., \& Bashline, B. (2019). Skin cancer: Prevention, FP Essentials, 481, 28-31.

[34] Reynolds, K., Buller, D., Yaroch, A., Maloy, J., Geno, C., \& Cutter, G. (2008). Effects of program exposure and engagement with tailored prevention communication on sun protection by young adolescents. Journal of Health Communication, 13(7), 619-636. DOI: 10.1080/10810730802412149

[35] Seidenberg, A.B., ., ., ., \& . (2015). Youth indoor tanning and skin cancer prevention: Lessons from tobacco control. American Journal of Preventive Medicine, 48(2), 188-94. DOI: 10.1016/j.amepre.2014.08.034

[36] Seite, S., Del Marmol, V., Moyal, D., \& Friedman, A.J. (2017). Public primary and secondary skin cancer prevention, perceptions and knowledge: an international cross-sectional survey. Journal of The European Academy of Dermatology and Venereology, 31(5), 815-820. DOI: 10.1111/jdv.14104

[37] Sideris, E., \& Thomas, S.J. (2020). Patients' sun practices, perceptions of skin cancer and their risk of skin cancer in rural Australia. Health Promotion Journal of Australia, 31(1), 84-92. DOI: 10.1002/hpja.253

[38] Stanton, W., Janda, M., Baade, P., \& Anderson, P. (2004). Primary prevention of skin cancer: a review of sun protection in Australia and internationally. Health Promotion International, 19(3), 369-378. 10.1093/heapro/dah310

[39] Stengel, F., \& Fernandez, F. (2005). Education and behavioural change for sun protection, Journal of Cosmetic Dermatology, 4, 83-88. DOI: 10.1111/j.1473-2165.2005.40206.x

[40] Suppa, M., Altomare, G., Cannavò, S.P., Capizzi, R., Catricalà, C., Colombo, E., Fargnoli, M.C., Fossati, B., Frascione, P., Lisi, P., Santini, M., Scalvenzi, M., \& Peris, K. (2014). Italian investigators for the Euromelanoma prevention campaign. The Italian Euromelanoma Day: evaluation of results and implications for future prevention campaigns. International Journal of Dermatology, 53(6), 699-706. DOI: 10.1111/j.1365-4632.2012.05783.x

[41] Szepietowski, J., Nowicka, D., Reich, A., \& Melon, A. (2004). Application of sunscreen preparations among young Polish people. Journal of Cosmetic Dermatology, 3(2), 69-72. DOI: 10.1111/j.14732130.2004.00119.x

[42] Thoonen, K., Osch, L.V., Vries, H., Jongen, S., \& Schneider, F. (2020). Are environmental interventions targeting skin cancer prevention among children and adolescents effective? A systematic review. International Journal of Environmental Research and Public Health,17(2), 529. DOI: 10.3390/ijerph17020529 
[43] Tizek, L., Schielein, M.C., Rüth, M., Szeimies, R.M., Philipp-Dormston, W.G., Braun, S.A., Hecker, C., Eberlein, B., Biedermann, T., \& Zink, A. (2019). Interest in skin cancer in urban populations: A retrospective analysis of Google search terms in nine large German cities. Acta Dermato-Venereolica, 99(9), 797-804. DOI: 10.2340/00015555-3214

[44] Trad, M., \& Estaville, L. (2017). University student awareness of skin cancer: Behaviours, recognition, and prevention. Radiologic Technology, 88(4), 373-377. PMID: 28298495

[45] Varedi, A., Secrest, A.M., Harding, G., Maness, L., Branson, D., Smith, K., \& Hull, C.M. (2018). Comprehensive outreach, prevention education, and skin cancer screening for Utah ski resorts. Dermatology Online Journal, 24(2).

[46] Watson, M., Holman, D.M., \& Maguire-Eisen, M. (2016). Ultraviolet radiation exposure and its impact on skin cancer risk. Seminars in Oncology Nursing, 32(3), 241-54. DOI: 10.1016/j.soncn.2016.05.005.

[47] Watson, M., Holman, D.M., Fox, K.A., Guy, G.P., Seidenberg, A.B., Sampson, B.P., Sinclair, C., \& Lazovich, D. (2013). Preventing skin cancer through reduction of indoor tanning: Current evidence. American Journal of Preventive Medicine, 44(6), 682-689. DOI: 10.1016/j.amepre.2013.02.015

[48] World Health Organization (2021). Cancer. Retrieved from: https://www.who.int/news-room/factsheets/detail/cancer

Received: 2021-06-08

Revision requested: 2021-06-30

Revised: 2021-08-11

Accepted: 2021-09-11

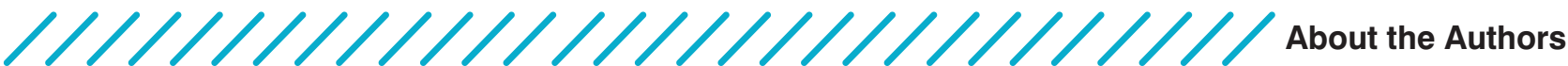

Jelena Krstić, PhD, Research Associate Economics Institute, Belgrade jelena.krstic@ecinst.org.rs

Jelena Krstic is employed at the Economics Institute in Belgrade, with the current position of Research Associate and as a member of the Scientific Board. She received her PhD digree in 2016 at the Faculty of Organizational Sciences, University of Belgrade, on the topic of integrated advertising. She is a Section Editor of the scientific journal Industrija. As a researcher and consultant, she participated in a number of scientific and practical projects, conducted in various economic areas. Her research interests are related to marketing communication and advertising, public relations and consumer behaviour. So far she has published two monographs and two chapters in international monographs, as well as more than fifty papers in international and national journals and proceedings of scientific conferences.

Nino Ćorić, PhD, Associate Professor
University of Mostar, Faculty of Philosophy, Bosnia and Herzegovina
nino.coric@ff.sum.ba

Nino Ćorić is an associate professor at the Faculty of Philosophy, University of Mostar and a visiting professor at the universities of Sarajevo and East Sarajevo. He is an author of about thirty scientific and professional papers in the field of communication and one textbook. His specific areas of interest are corporate communication, internal communication and socially responsible business. He is the editor of the library Komunikacij@ of the publishing house Synopsis (Zagreb-Sarajevo). He is a member of the editorial board and international councils of several scientific journals in Bosnia and Herzegovina and abroad. He is Editor-in-chief of the scientific journal South Eastern

European Journal of Communication. He has many years of managerial experience in the field of marketing, public relations and corporate communications. He has won professional awards in Bosnia and Herzegovina and abroad.
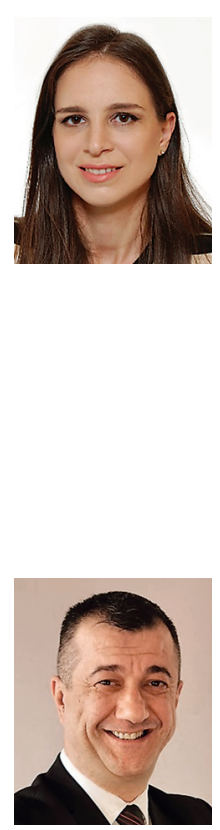